\title{
Teaching as Authentic Practice in the Graduate Student Supervisory Relationship
}

\author{
James Field, Galicia Blackman, and Kaitlyn Francois, University of Calgary, \\ Canada
}

\begin{abstract}
This article is the outcome of a co-inquiry with students where shared interests about student learning, students as partners, and a hermeneutic lens shaped the main research questions: What are graduate students' experiences of the supervisory relationship and what happens inside the relationship in terms of learning and student success? We conducted 16 in-depth interviews with graduate students across various departments and programs. From these interviews we theorized that it may be more appropriate to speak of graduate supervision as a practice that produces internal and external goods. We found that it may be more appropriate to speak of the pedagogy as mentoring. We believe our research findings extend understanding of the supervisory relationship, contribute to the concept of teaching, and expand the idea of partnership with students in higher education wherever faculty and students find themselves in supervisory relationships. This is relevant to SoTL because it allow us to think about the nuances in the word teaching and to consider how an examination of supervisory relationships in higher education can expand the way we talk about teaching and learning in higher education.
\end{abstract}

Keywords: student experience, supervision, mentoring, authentic practice

CC-BY-NC-ND Licence 4.0 This is an Open Access article distributed under the terms of the Creative Commons - Attribution License 4.0 International (https://creativecommons.org/licenses/by/4.0/), which permits copy and redistribution with appropriate credit. This work cannot be used for commercial purposes and cannot be distributed if the original material is modified. 


\section{INTRODUCTION}

In this article, we present the results of a study that was a co-inquiry with graduate students (see Cook-Sather et al., 2014; Hancock \& Lubicz-Nawrocka, 2018; Welikala \& Atkin, 2014). As co-investigators, our shared interests about student learning, students as partners (Healey et al., 2014), and a hermeneutic lens (Moules et al., 2015) shaped our inquiry into students' experiences of being supervised. The main research questions are as follows:

- What are graduate students' experiences of the supervisory relationship?

- What happens inside the relationship in terms of learning and student success?

- What are the conditions in which students learn and become successful?

- What are the experiences within the relationship that hinder students' learning experiences?

As Welikala and Atkin (2014) have pointed out, attention to the student experience in higher education has gained momentum over the past few decades, especially in terms of the idea of partnerships between faculty and students. CookSather et al. (2014) looked extensively at student-faculty partnerships and concluded that traditional ways of eliciting information from students do not approximate genuine partnerships. Unfortunately, this student-faculty relationship often appears as simply transactional while genuine partnership "is based upon the principles of respect, reciprocity, and shared responsibility" (Cook-Sather et al., 2014, p. ix). This description of student-faculty partnership speaks to what should be occurring within the supervisory relationship.

Although the supervisory relationship deviates from traditional classroom learning, we began our inquiry with the recognition that the individual pedagogy within the supervisory relationship warrants attention in the Scholarship of Teaching and Learning (SoTL) literature, especially when considered within the students-as-partners framework. The students-as-partners framework (Cook-Sather et al., 2018) advocates for what students can actively contribute to research around teaching and learning in higher education. This kind of partnership can shift the focus away from faculty to allow students to be more active participants in research with the hope that students can be more intentional in their learning practices and activities. The idea of such a partnership has implications for graduate students who are learning how to conduct research, how to integrate into the academy, and how to be good colleagues. Although there are a range of opportunities where a graduate student can develop this scholarly identity, their supervisor is often the first trusted point of entry into that development. This is not to suggest that the supervisory relationship starts off with a sense of partnership. Through our conversations with 
graduate students in this research and through our team conversations in conducting the research, we found partnership to be a developmental process that needs certain conditions and practices in order to emerge.

These conditions and practices may be presented in documents, such as checklists for guidance and institutional agreements both supervisors and students are required to sign (University of Calgary, 2018). One such checklist states that:

Graduate students hold the primary responsibility for completion of their degree. Graduate study requires independent learning, and for thesis based students, constant collaboration with one's supervisor. For full-time thesis based students, there is an expectation to meet the regulated deadlines established by the Faculty of Graduate Studies, and to maintain open communication with the supervisor. The student must actively seek to expand their knowledge and is expected to solve problems independently, to pursue opportunities to learn specific skills, and to become familiar with a body of knowledge, with the ultimate goal of producing and defending a thesis. (University of Calgary, 2018, para. 2)

The checklist also indicates that supervisors should guide students (University of Calgary, 2018). While such checklists establish some basic parameters of the supervisory relationship and advise students that they are to consult administration if there are unsatisfactory matters, these parameters do not get at the experience within the relationship. Our approach to questioning student experience in the supervisory relationship presents an alternative angle to the ways in which the graduate student experience is typically addressed in research while complementing some of the themes such research has usually addressed.

\section{LITERATURE REVIEW}

Within the academic literature, scholars have suggested that supervisory relationships are crucial to student success (Delany, 2009; González-Ocampo \& Castelló, 2019; Richards \& Fletcher, 2020; Roach et al., 2019; Sverdlik et al., 2018). However, what happens within that relationship is considered to be "a private affair" (Horsfall, 2008, p. 6), and the "invisible pedagogy" (Johnson et al., 2000 , p. 143) that occurs there is not typically spoken about openly. Agné and Mörkenstam (2018) have inquired into what kinds of supervision are successful, and this study sought to add to such discourse by providing insight into what students regard as successful. According to the literature, supervisory relationships are crucial to student success in terms of mentoring, guidance, and structure (Boucher \& Smyth, 2004; Horsfall, 2008; Lechuga, 2011; Lunsford, 2012; Mansson \& Myers, 2012; Omar et al., 2016; Paglis et al., 2006; Rugg \& Petre, 2004; Sarikaya et al., 2017). These themes appeared in our participants' 
experiences. On the other hand, the themes of abuse, exploitation, and neglect also feature in the literature (Ellis, 2001; Glaser \& Thorpe, 1986; Goodyear et al., 1992; Jacobs, 1991; Sullivan \& Ogloff, 1998). We did not encounter themes of abuse or exploitation in our research, but there were experiences that resembled neglect.

While some supervisors do not take kindly to others looking in on the privacy of supervisory meetings (Watts, 2008), research into the graduate student experience has value for several groups. Universities tend to seek ways to make the most of their investments in supervision and teaching because they expect to reap the benefits of research breakthroughs, and to do so they aim to ensure that students are progressing within reasonable timelines (Agné \& Mörkenstam, 2018). Furthermore, when students take an inordinately extended time to complete their studies or even fail to complete their studies, the emotional labour and career stagnation can be damaging (Agné \& Mörkenstam, 2018). The anecdotes about the supervisory relationship that informed our research findings have specific value for SoTL because they allowed us to think of teaching beyond the scope of the traditional classroom context. As Poole (2018) noted, "intuition, anecdotes, and observation" are suitable sources for SoTL work (p. 6). For us, the opportunity to think about teaching within the supervisory relationship has implications for what we imagine SoTL to be-insight into curricular practices that support student learning, flourishing, and becoming.

The types of studies we consulted as background analysis for this research tended to be broad surveys of student experience, such as Dericks et al. (2019) and González-Ocampo and Castelló (2019), student satisfaction surveys, studies of critical incidents, case studies, and self-studies. We noticed that most studies focused on doctoral students and that masters students tend to be marginalized in the research. Our research sought to address this marginalization by including both masters and doctoral students. Furthermore, we believed that by conducting a qualitative study where we pursued detailed descriptions of student experiences, we had the prospect of teasing out the nuances of the broad findings of survey studies. For example, some survey studies focus on student satisfaction, correlating this satisfaction with supervisory support (Dericks et al., 2019), while other studies have noted that students demonstrate a range of responses to unsatisfactory supervision where they may enact strategies to cope with their perceptions of the negative experiences (González-Ocampo \& Castelló, 2019). We believe our research findings extend understanding of the supervisory relationship, contribute to the concept of teaching, and expand the idea of partnership with students in higher education wherever faculty and students find themselves in supervisory relationships. 


\section{Methodology}

Upon approval from our ethics board, we conducted 16 in-depth interviews with graduate students across various departments and programs at the University of Calgary between October 2018 and April 2019. We sought to recruit participants who had experienced at least one year of graduate supervision and in doing so, we did not apply any rigid exclusion criteria. We recruited domestic and international students in masters and doctoral programs. The participants' program progression ranged from year 2 to 7 of study.

Our interviews were guided by an applied hermeneutic research methodology in alignment with our research lens. Some of the foundational understandings and theories for the research included ideas that the partnership between student and supervisor is dialogical, the supervisory relationship has a long history steeped in traditions within the academy, and the relationship is driven by the language used to build rapport and usher a graduate student into these traditions of the academy. All study team members had some prior experience with hermeneutic research, thus we piloted our interview approach by interviewing each other using draft questions and later refined our questions based on this pilot process. Interviews were semistructured, conducted in a mutually agreed upon location, and lasted between 60 and 90 minutes. All interviews were conducted by the two graduate students on the research team with the goal of allowing participants to share their experiences openly and to avoid feelings of intimidation if interviewed by the graduate supervisor/program director on the research team.

We posed a variety of guiding questions that focused on the themes of students' hopes, goals, and expectations for their graduate program and for their supervisor, as well as the ways in which teaching and learning were demonstrated or supported within the supervisory relationship. We also asked students about feelings and emotions such as comfort, safety, respect, trust, enjoyment, inspiration, and enthusiasm, and whether these were experienced in the context of the supervisory relationship. Finally, we asked students directly for their recommendations and advice for supervisors about what it means to be a good supervisor and provide meaningful supervision. Through these guiding questions, we sought to better understand each student's expectations for their academic program and their relationship with their supervisor. According to standards for the ethical conduct of research, we provided participants with copies of their transcripts to confirm their consent and reaffirm permission to be quoted in reporting the research. 


\section{ANALYTiCAl Approach}

We began by reading through the transcripts from different positionalities (i.e., graduate students and graduate supervisor/program director) to avoid a single interpretation or "group think." We did not want to silence diverse perspectives or prevent unique understandings from emerging from the data. In this process we found ourselves asking, what experiences strike us as significant when we read as graduate students and as a graduate supervisor/program director? We then engaged in a three-way analytic/reflective discussion around our individual interpretations of what was significant in the student testimonies. We asked ourselves what were the students speaking about in their recounting of their experiences and what in their testimony struck us as significant. Integrating our perspectives through dialogue helped us to see things we may not have seen individually, resulting in an outcome that reached beyond our individual interpretations.

We then reread the transcripts to validate and verify our findings. Through discussion and repositioning, we were able to elaborate on the significant features of student experience and what students valued. Using hermeneutic analytical approaches (Moules et al., 2015) and framing the analysis around the research question of what constitutes student experience within a supervisory relationship, we questioned what emerged as valuable and meaningful in the supervisory relationship for all research team members, resulting in a discussion of values and goods. Based on our discussions of what was valuable in the supervisory relationship, one of the team members proposed an article by Kreber (2015), which supported what we found to be significant in the study around the idea of what is good for students.

After the second reading, group discussions, and consideration of Kreber (2013; 2015), we theorized that it may be more appropriate to speak of graduate supervision as a practice that produces internal and external goods. We then found to speak of the pedagogy as mentoring. This is relevant to SoTL because it allowed us to think of the nuances in the word teaching and to consider how an analysis of supervisory relationships in higher education can support how we interpret teaching and learning in higher education.

\section{Authentic Practice}

We framed our findings in terms of what Kreber (2015) described as the goods within authentic practice. Kreber (2015) argued that "SoTL emerges as an 'authentic practice,' whereby scholars of teaching find purpose in furthering students' important interests" and that "authenticity then emerges as a useful construct for understanding both the practice of SoTL and the students' important interests" (p. 109). For our study, these interests can be framed as what good comes out of the supervisory relationship. Kreber (2013) has also asked about the nature 
of authenticity:

What does it mean to be authentic? Why should it matter whether or not we become more authentic? How might authenticity inform and enhance the social practice of the scholarship of university teaching and, by implication, the learning and development of students? (p. 1)

We do not explore the concept of authentic practice for this paper because our discussion is influenced by the recurring themes in the interviews with students. Nevertheless, these are the important questions for thinking about supervision as teaching. Elaborating on this, Kreber (2013) explained that four main ideas emerge from thinking about authentic practice: "teaching, scholarship, authenticity, and practice" (p. 1). We take up Kreber's (2013) theorizing to think about the supervisory relationship as a practice, which is driven by what is deemed to be good:

Following a less conventional understanding of a practice I also want to point to the fact that teaching and scholarship are activities in which we, together with other actors, are personally invested and pursue out of an inner motivation and disposition to do good work. (p. 1)

Building on that idea, according to Kreber (2015), the essence of practice as conceptualized by Aristotle, MacIntyre, and Dunne is that it is guided by an ethical aim, it is based on specific virtues, and it generates internal and external goods.

\section{MEANING IN THE STUdents' EXPERIENCES: THE INTERNAL AND EXTERNAL GOODS}

In the process of undertaking a study shaped by hermeneutic research principles, we sought rich descriptions of graduate student experiences. This richness led to diverse meaning about how students were experiencing supervision. At the same time, there was commonality manifested in the themes that emerged. Kreber (2015) provided us with a way to frame the commonality by presenting a view of supervision as practice:

Practices thus take place within a community. Involvement in the practice helps us to realize certain goods and leads us to conceptualize these goods in a particular way. The goods internal to the activity in which we are engaged become available to us as we exercise certain "virtues" necessary for achieving the standards of excellence associated with the practice. (p. 102) 
This point of view was useful to help us note that what students valued, in the process of becoming within the academy, was contingent on the goods that emerged from the practice of supervision.

\section{The External Goods}

We came to theorize about the external goods as those that students valued when they were able to experience the pleasure and recognition that comes from "getting somewhere" in their degree program or "producing" something. We recognized this in the ways that students spoke of academic achievement, meeting milestones (e.g., coursework, candidacy, obtaining the degree), securing prestigious funding, and publishing. For example, North ${ }^{1}$ was pleased with his supervisor's responsiveness to meet his program goals:

So if something is pressing-manuscript review, proposal stuff, any committee meetings, prep, candidacy work for the PhD students in our lab, anything like that where there is a timeline or an academic requirement - my supervisor he'll definitely set aside time for that.

Laurie appreciated how her timeline was progressing:

Yes it is working out. It's going well. Oh, I finished my candidacy exam within the deadline. I'm finishing my research project now. I am at the process of analysis, which is pretty neat based on my deadlines to present next year at a brief conference, so it's going pretty well. I'm happy with her and no concern, no issues.

Venus felt satisfied that progress was occurring when her goals for a meeting were accomplished:

That's how I can say it was successful if we cover what was expected, if we ended up with the paper that we needed, or if I could solve my questions, or yeah, if we decided to do something, right? In terms of, um, achieving what we expected for these meetings.

Aruna's experience, revealing a shortcoming, indicated the bare minimum that she expected to occur:

So I guess that was my expectation, really to support me through the whole process. If that meant just completion of coursework or identifying knowledge, just the whole thing. I don't wanna say I wanted to have my hand held throughout the process. I'm a student. I need to learn. I get that.

\footnotetext{
${ }^{1}$ All names are pseudonyms, and participants included here consented to be quoted.
} 
But I definitely felt they would have been side-by-side with me through every process. Yeah, that was my expectation.

The external goods may be seen as commensurate with what the supervisory checklist emphasized:

The supervisor must be available for mentoring, and to provide guidance, advice and educational opportunities. The supervisor is expected to provide feedback and minor editing of the student's thesis, scholarship applications, grant proposals, abstracts and manuscripts for publication. The intellectual property that is expected to result from, or is necessary for, the student's thesis work should be discussed in advance and agreed upon between the student and the supervisor. (University of Calgary, 2018, para. 3).

However, for our student participants, the external goods, while necessary, were not quite sufficient. There was more to the supervisory relationship than checking off accomplishments that met with a prescribed checklist.

\section{The Internal Goods}

We came to recognize the internal goods within the relationship as the students' pleasure that comes from flourishing. It manifested as feelings of growing into a new self or transformation, becoming skilled at all features of scholarly inquiry, being empowered to pursue passionate knowledge, feeling confident to pursue a topic that one loves, in a way that one finds deeply satisfying, and developing a sense of belonging as a scholar. Adel noted that,

It was the first time in my life that I would sit with a book or a couple books on the deck in my house [pause], feel the breeze, feel the sun, have my book. It's like, I feel like I did nothing all week, but actually I came to some important conclusions about my topic. I came to very important conclusions thanks to that permission that it wasn't about working all night to produce a paper. ... I do a lot of good thinking and of course while I'm writing, as everybody does. But he removed the whole guilt factor.

So, if there was anything, I think more opportunities for faculty and staff - number one - to interact together. Faculty and students to interact together. But also to, to purposely insert language of caring, nourishing, and mentoring and transforming.

His advice, his wisdom-has transcended. He's transforming me as a person. It's not just about the $\mathrm{PhD}$ letters and convocation. 
Adel described a common thread we found among student participants who voiced a desire for supervisors to make a conscious effort to mentor and nourish their students' efforts to become or "transform" into better scholars. For some students, this feeling of being accepted as valuable members of the academic community and feeling like they belonged was something they appreciated most coming from their supervisor, especially if this level of respect was established early on in their relationship. This provided students with a sense of acceptance and promoted confidence in their abilities to move forward with their graduate work. Rushin described it in terms which spoke to the sense of becoming:

I feel like really welcomed into the field. It's very comforting to be spoken of in terms of you belong, like you already belong. It's not as if you have to pass some kind of test or judgement to get in. Just treating me like I'm part of the community is really, yeah, that's definitely made me feel more feel like I can do a PhD.

We found that for student-participants, internal goods were also an extension of the external goods related to "accomplishing something" or meeting milestones. Students spoke of their desire to be encouraged by their supervisor to feel pride and enthusiasm for their graduate work. It was desirable for supervisors to not only support students in their efforts to remain passionate about their studies, but to also be role models by demonstrating enthusiasm for and competence in their own academic pursuits. Rushin felt energized by the supervisor's interest in her work:

Yeah, because he's a very passionate person oftentimes he would make some of the things I'm saying feel more exciting. Sometimes I would think that there are parts of my work that feel very dull or unimportant, and he would change that around completely.

We found there was a common thread woven throughout all of the interviews when students spoke of the human side to graduate supervision. This was reflected in a variety of ways, including wanting the supervisor to pay attention to the student's well-being, life, and family outside of their "academic life," being sensitive to the multitude of demands placed on mature students in graduate school, and being available and willing to listen to the student's concerns and challenges, triumphs and joys. Venus noticed the supervisor's emotional side and described it as follows:

She tries to be very human. Very sensitive, sensitive about my well-being first of all ... when she knew that I was having certain difficulties. What happened with that? Could you manage that? Do you need any help? That's like the human part first and then the academic one. 
It's supportive. Cares about the students. Right? Beyond the academic thing I would say. Ah, shares their knowledge, their expertise ... in a way it is demanding. Challenges you to achieve things. So, not do what you can do - it's you're able to do more. So, it challenges you, it opens more possibilities, it creates higher expectations, um, to achieve big things.

One student articulated a situation that points to a sense of loss or disappointment in missing out on this human connection. Instead of feeling a sense of comfort with and respect for the supervisor, the student expressed a disconnect between how she thought she would come to know her supervisor and what actually happened:

I always expected that the first day I met her I saw all these little cool things in her office and she was - this student gave me this, this student, and I was, I wonder what I will get her, and I do not want to get her anything. I know that I have to, and I probably will because that's the norm. I am the student. She is the supervisor. The politics where I want to go in life. I have to play my cards right. You gotta think about all those things. But I would say take ownership of your learning and your expectations of yourself and your supervisor, and have that conviction behind them because I lacked that conviction for sure.

\section{Flourishing Versus the Effects of a Submerged or Thwarted Self}

Figure 1. Flourishing: Recurring Themes of Expectations and Experiences of the Participants in our Study.

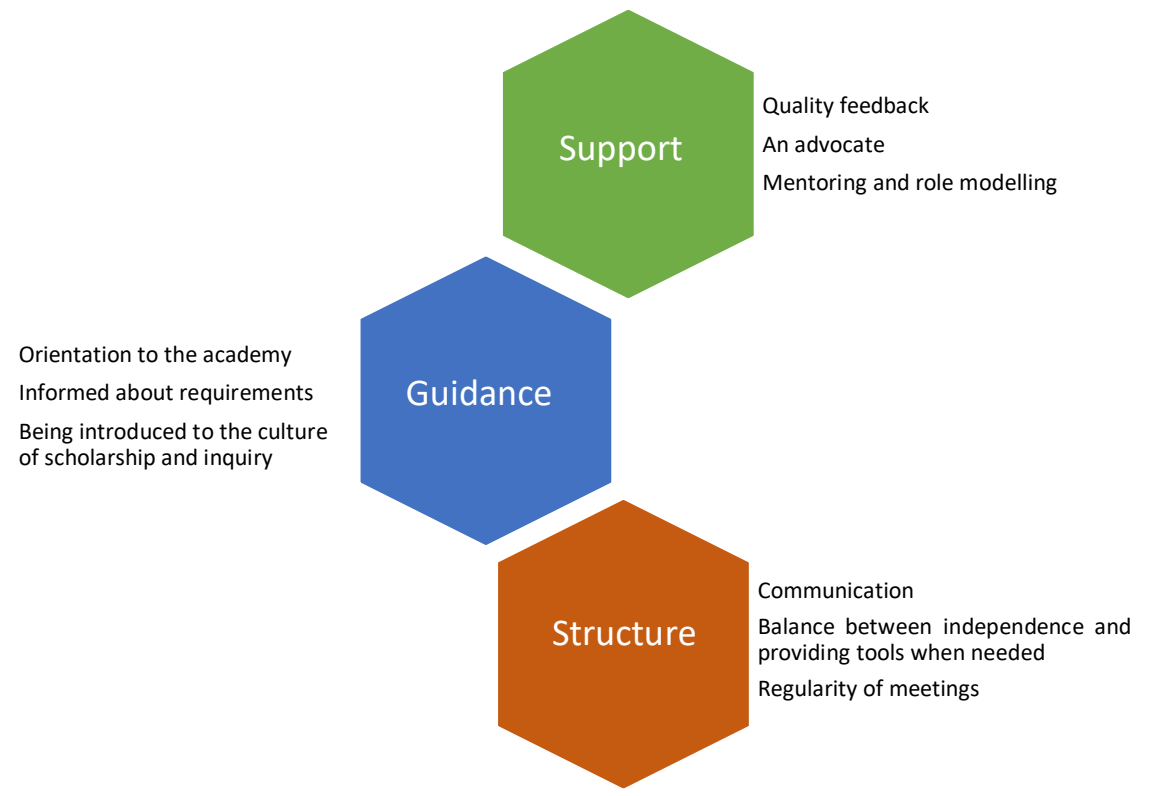


The unfolding of students' expectations and the interplay between external and internal goods contributed to students' ideas of what it means to be successful in an academic program. The fulfillment of expectations was reflected in students recognizing when they were flourishing because they met with experiences represented in Figure 1.

These expectations and experiences indicate the complexity of the "invisible pedagogy" involved in the supervision of graduate students (Johnson et al., 2000, p. 143). This is not meant to imply that students who felt they were met with internal and external goods were automatically flourishing. We noted that even in successful and safe supervisory relationships, there were feelings of fear, trepidation, insecurity, discomfort, and anxiety. We observed that when the relationship was not working out, we saw in students the effects of a submerged or thwarted self. Students' hopes and dreams for graduate school, their understanding of institutional requirements, and what they heard their peers were experiencing, culminated in a sense of feeling like they did not belong. For example, Molly disclosed,

Well, I mean I appreciate the time. She gave me resources, you know, some paper resources and all that kind of thing. Like it's not like she's not being helpful. And I know that she can't do the work for me. But I don't feel like I can phone her up or email her and say, "Like I'm really not getting anywhere and I need some help." I just don't feel I can do that ... . I just kind of feel like, well most of the time I feel like, oh my god I've got so much work to do. I don't know how I'm going to do this all [laughs].

Um, I don't feel great about it, but I don't feel like she's ... you know, again, she's doing what she feels is like her job, right? Um, and maybe I, my expectations are too high ... I think that would be a real perk. I don't feel unsafe. I don't feel [pauses] disrespected in any way. Like, you know, my supervisor's a very nice person. Um, I just don't feel any connection [gets teary eyed].

As well, Laurie shared a similar sentiment:

I would write to my supervisor about the proposal, with the changes or whatever was suggested by the team for three months and my supervisor would say, "your proposal looked amazing, and I'm ok fine, all ready to go to committee," when I got to the meeting, the committee were all on the other side. One committee member would say something different, the other committee member would say something different, and my supervisor would not support me. They were just saying things like- this 
is missing, this is missing - and she wasn't saying anything to support me. She wouldn't say a word. Yes, I worked with her on that proposal. I take responsibility, but there was no support from her.

These students show how seemingly supported students can still feel thwarted. The experience of having only external goods can lead to frustration with the experience of internal goods. The underlying effect is that who a graduate student becomes as a person and scholar is best determined within the relationship of student and supervisor, not necessarily the experience of graduating with a degree or reasonable time to completion.

What counts as working well in the supervisory partnership has to be decided within the relationship. The practice of teaching within the supervisory relationship is the attainment of a balance of finding what works for each student. Sometimes it is a balance between independence and dependence or structure and freedom. Ultimately, it is an evolving dynamic that seems to come from an ongoing relationship and has to work itself out (i.e., from teacher/instructor to mentor). It is an open-ended process, not a predetermined one, which sees the outcome as the making of a student or scholar.

\section{IMPLICATIONS FOR IMAGINING SUPERVISION}

In our study we avoided the discourse on models of supervision (Delany, 2008; McCallin \& Nayar, 2012) and best practices in supervisory relationships because we sought to describe students' experiences and give voice to the whispers in halls, the sense of disempowerment that halted students' ability to openly articulate their experiences, and conversely, what contributed to students feeling that they could belong to the academic community. Delany's (2008) review of literature on supervision was critical of the traditional use of lists that outline graduate student proficiencies, and Lee (2008) has pointed to the shortcomings of using lists to chronicle and evaluate student development. The fact that we have checklists governing the beginning of a relationship (University of Calgary, 2018) suggests that such a framework still holds sway over what occurs in the relationship. Throughout our study, some participants made mention of the checklist as a medium for initiating or directing the conversation with the supervisor upon their first meeting. However, it did not emerge as a major theme, so we refrain from making any claims about the concrete influence the checklist may exert in the relationship, especially as the relationship progressed over time.

The implications of this research, intersecting with the themes emerging from the academic literature, have led us to make critical observations about the supervisory relationship. Are supervisors aware of the work of power within the relationship? We think this is worth considering since asymmetrical power relations 
may, perhaps unbeknownst to the supervisor, affect students' sense of belonging, productivity in their academic pursuits, and sense of becoming as graduate scholars. Does this power differential factor into how the relationship is organized? Students are certainly conscious of the asymmetrical power in the relationship, of which we were informed by some of the student participants in this study.

Relating to the possibilities for how relationships are organized, can this be done around the student's emerging being or an emerging self? The institutional mandate might privilege milestones and other external goods, but are supervisors aware of how these goods are tied to students' hopes and dreams for the future? Is futureoriented talk part of supervisory talk? We wonder if the student's becoming and flourishing is considered or planned for within the unfolding of the relationship. Does this sync with the supervisor's own sense of what it means to become a scholar?

Internal and external goods are not contrary or mutually exclusive. They are pieces of the whole experience of becoming a scholar or professional, and it may be worthwhile to think of the supervisory relationship not as fixed, but capable of growing to respond appropriately to a student's and supervisor's needs and priorities. The overall process of supervision and student experience as a whole must acknowledge that students may not always have a positive experience or smooth road (i.e., ups and downs are expected), but in the end the relationship needs to be evaluated in terms of whether it was a worthwhile and fulfilling experience for the student.

We acknowledge that because we did not research supervisors' experiences of the relationship, there is scope for further research into supervisors' perspectives. For example, Åkerlind and McAlpine (2017) made a case for attention to how professional development for supervisors needs to be accompanied by consideration of the aims of academic supervision. There is scope to think of supervision as having a pedagogy. Additionally, even though some of our participants experienced co-supervision, we did not address it as distinct from single supervision, even while there is research that looks into co-supervision as distinct (Manathunga, 2012).

We would like to see complementary research on supervisors' experiences, specifically around their awareness of students' internal and external goods. Beyond that, it may be worth exploring what internal and external goods are important to supervisors and if they are congruent or at odds with those of students. Does the supervisor hold the same values regarding what is good or necessary and what is not within the relationship?

Throughout our research, although we did not set out to explicitly ask about the future and the imagined self that would result from having been a graduate student, we noted glimpses of this self-projection in how students spoke about the emotional 
labour or reward of the relationship and how they were emerging differently from how they came into graduate school. It is interesting to consider the lessons students may take away from their relationships with their supervisors in terms of their own personal development. As many graduate students may eventually transition into a supervisory role themselves, we wonder what conclusions they may draw from their own student experience and if this would translate into the development of their own supervisory practices. This becomes a question of whether good habits are generated versus bad habits being replicated and whether the power differential we mentioned is considered in the formation of these habits and practices.

Even while we used Kreber (2013) to theorize about the diversity among our research participants, we did not address Kreber's idea of teaching practice - that teaching is governed by an ethical aim, and it is based on particular virtues. Our unanswered questions are as follows: What is the ethical aim of the supervisory relationship and what are the virtues which emerge in the development of the relationship? We believe these questions have implications for how we imagine the scholarship of teaching and learning. Does the discourse of virtues have a place in teaching in higher education and should there be a place for such discourse? Can we begin research into teaching and learning by framing the ethical aim? For the supervisory relationship, we mean the ethical aim for both students and supervisors. As Halse (2011) noted, "Regardless of supervisors' discipline, position in the academic hierarchy or supervisory experience, the analysis indicates that supervisors' learning experiences shape their subjectivities and identities, and that supervision is an ongoing ontological process of 'becoming a supervisor"' (p. 557).

Halse's (2011) perspective intersects with Kreber's (2013) idea of practice and the ethical aim because in our research we noticed how the students' experiences of the practice of supervision contributed to the making of a student and the identity of becoming a scholar, what Lee (2008) called enculturation, which is the experience of a student being "encouraged to become part of the disciplinary community" (p. 270). Although we asked students what advice they would give to supervisors, we did not set out to consider the making of a supervisor in our research. However, our interviews had an interesting sub-theme where we noted that students were deeply concerned about their supervisors' success, reputation, or well-being, and how the students might support their supervisors' work. The students' concern went beyond a sense of obligation to their supervisors. The collegiality within the relationship is worth exploring further. It may have implications for the teaching and learning conditions within the relationship. 


\section{IMAGINING GRADUATE STUDENT SUPERVISION: IMAGINING AUTHENTIC INQUIRY}

Conceptualizing the practice of supervision as a partnership that can produce internal and external goods may evoke connotations with transactional consumerism; however, we are thinking of it along the lines of what Waghid (2006) believed is a call for "higher levels of freedom and friendship to become more prevalent in postgraduate student supervision" as opposed to business-like, transactional encounters (p. 427). Richards and Fletcher (2020) have made a case for approaching supervision as "critical friendship," which is marked by the supervisor's supportive abilities, the collegiality with students, and the recognition of the appropriate time to relinquish control over students as they engage with challenges. These perspectives suggest that the potential for collegiality in the supervisory relationship can offer insight into the students-as-partners movement within SoTL work. We do not know if higher education is ready for these widespread kinds of partnerships although they might already be occurring, as seen in some of our interviews. However, the discourse of mentoring might be more palatable to supervisors and institutional conventions. The discourse of mentoring, represented by the language offered by several of our student participants, may help us conceptualize the virtues and the ethical aim of a teaching and learning relationship in supervision. Perspectives on the connections between supervision and pedagogy are diverse (McCallin \& Nayar, 2012), so there certainly is scope to think of supervision as pedagogy and to conduct inquiry into the supervisory relationship as pedagogy.

When we considered what teaching within the supervisory relationship means to students, we noted that the theme of mentorship was more appropriate to describe what students bore witness to in terms of their learning, flourishing, and becoming. Lechuga (2011) theorized that graduate student mentorship may be thought of in terms where faculty members can be seen as "allies, ambassadors, and masterteachers" (p. 757). It may require some risk to develop these values, which lead to meaningful, mentoring partnerships (Hancock \& Lubicz-Nawrocka, 2018), but that is part of the ongoing work that moves us into the realm of imagining what is possible in the practice of these partnerships and not limiting the view of these partnerships to checklists and best practices. A guidelines list does not state or determine the ethical aim of the supervisory relationship. That is something to be worked out within the relationship as both supervisors and students exercise "authenticity and phronesis (or good practical judgement)" (Kreber, 2013, p. 102). The outcome of being mentored, alongside students' expectations for graduate school, is that students see opportunities or imagine that they are something different or become someone different. As a fulfillment of the imagination, the relationship can lead to students flourishing when possibilities are opened up for them, and they become different, learned, or accomplished. The experience of a student becoming oriented into the ways of the academy (Lee, 2008) and the idea 
of a supervisor "becoming a supervisor" (Halse, 2011, p. 557) is an experience that is shared with students, and awareness of this process could allow for genuine dialogue between faculty and students.

When Kreber (2013) asked whether the scholarship of teaching and learning can be thought of as "MacIntyrean practice" (p. 102) in that it is guided by an ethical aim and comprised of internal and external goods, we thought that we might add supervision (a research and teaching relationship). When supervision is thought of in terms of teaching and mentoring, we feel it ought to be considered within the scholarship of teaching and learning. Supervision and the practices therein need not be hidden pedagogies, but they can be sites for "inquiry focused on student learning" (Felten, 2013, p. 122). An inquiry approach to the partnership in the supervisory relationship, within the relationship itself, is where we think that both students and supervisors can benefit. As Kreber (2013) suggested, this could involve "growing into ourselves and becoming critically aware of the inner motives that guide us in this work" (p. 104). This approach would be broader than the description of research being "grounded in context" (Felten, 2013, p. 122). This may mean we need to expand Felten's (2013) "principles of good practice” (p. 122) in SoTL to include a principle whereby the supervisor's or instructor's learning or practice undergoes some kind of shift. In hermeneutic work, to understand means to understand differently (Moules et al., 2015). Kreber's (2015) position echoed this:

The person who develops phronesis does not just acquire new knowledge; he or she is also changed as a result of this process. The person engaged in the practice of SoTL, and who through this involvement develops phronesis, is implicated in a self-transformative process (Kreber, 2013; Mezirow, 1998), moving towards greater authenticity. Striving towards certain standards of excellence also involves extending and transforming oneself through this process. SoTL, thus conceived, is essentially a process of becoming. (p. 110)

If students and supervisors/instructors are unchanged by the partnership and the inquiry therein, what have we learned and who have we become?

Disclosure: There are no known conflicts of interest.

\section{ACKNOWLEDGEMENTS}

This research was funded by the Taylor Institute for Teaching and Learning. 


\section{AUTHOR BIOGRAPHIES}

Dr. James Colin Field is an Associate Professor and one of the Graduate Program Directors at the Werklund School of Education. His research interests include curriculum studies, collaborative, school-based research, interpretive research, and teacher education. Contact: jfield@ucalgary.ca

Galicia Blackman is a doctoral candidate at the Werklund School of Education, specializing in Curriculum and Learning. Her graduate research uses hermeneutic research to examine dialogic pedagogy in language arts and literary studies. Contact: galicia.blackman@ucalgary.ca

Kaitlyn Francois, MN, RN, is a doctoral candidate in the Faculty of Nursing at the University of Calgary. Her current research is a hermeneutic study exploring parents' experiences of having a child survive a malignant pediatric brain tumour. Contact: kdfranco@ucalgary.ca 


\section{REFERENCES}

Agné, H., \& Mörkenstam, U. (2018). Should first-year doctoral students be supervised collectively or individually? Effects on thesis completion and time to completion. Higher Education Research \& Development, 37(4), 669-682. https://doi.org/10.1080/07294360.2018.1453785

Åkerlind, G., \& McAlpine, L. (2017). Supervising doctoral students: Variation in purpose and pedagogy. Studies in Higher Education, 42(9), 1686-1698. https://doi.org/10.1080/03075079.2015.1118031

Boucher, C., \& Smyth, A. (2004). Up close and personal: Reflections on our experience of supervising research candidates who are using personal reflective techniques. Reflective Practice, 5(3), 345-356. https://doi.org/10.1080/1462394042000270664

Cook-Sather, A., Bovill, C., \& Felten, P. (2014). Engaging students as partners in learning and teaching: A guide for faculty. Jossey-Bass.

Cook-Sather, A., Matthews, K. E., Ntem, A., \& Leathwick, S. (2018). What we talk about when we talk about students as partners. International Journal for Students as Partners, 2(2), 1-9. https://doi.org/10.15173/ijsap.v2i2.3790

Delany, D. (2009). A review of the literature on effective PhD supervision. Trinity College Dublin.

https://www.tcd.ie/CAPSL/assets/pdf/Academic\%20Practice\%20Resource s/Effective Supervision_Literature_Review.pdf

Dericks, G., Thompson, E., Roberts, M., \& Phua, F. (2019). Determinants of PhD student satisfaction: The roles of supervisor, department, and peer qualities. Assessment \& Evaluation in Higher Education, 44(7), 10531068. https://doi.org/10.1080/02602938.2019.1570484

Ellis, M. (2001). Harmful supervision, a cause for alarm: Comment on Gray et al. (2001) and Nelson and Friedlander (2001), Journal of Counseling Psychology, 48(4), 401-406. https://doi.org/10.1037/0022-0167.48.4.401

Felten, P. (2013). Principles of good practice in SoTL. Teaching \& Learning Inquiry, 1(1), 121-125. https://doi.org/10.20343/teachlearninqu.1.1.121

Glaser, R. D., \& Thorpe, J. S. (1986). Unethical intimacy: A survey of sexual contact and advances between psychology educators and female graduate students. American Psychologist, 41(1), 43-51. https://doi.org/10.1037/0003-066x.41.1.43

González-Ocampo, G., \& Castelló, M. (2019). How do doctoral students experience supervision? Studies in Continuing Education, 41(3), 293-307. https://doi.org/10.1080/0158037X.2018.1520208

Goodyear, R. K., Crego, C. A., \& Johnston, M. W. (1992). Ethical issues in the supervision of student research: A study of critical incidents. Professional Psychology: Research and Practice, 23(3), 203-210. https://doi.org/10.1037/0735-7028.23.3.203 
Halse, C. (2011). 'Becoming a supervisor': The impact of doctoral supervision on supervisors' learning. Studies in Higher Education, 36(5), 557-570. https://doi.org/10.1080/03075079.2011.594593

Hancock, J., \& Lubicz-Nawrocka, T. (2018). Creating spaces: Embracing risk and partnership in higher education. Teaching and Learning Together in Higher Education, 1(24).

Healey, M., Flint, A., \& Harrington, K. (2014). Engagement through partnership: Students as partners in learning and teaching in higher education. The Higher Education Academy. https://www.heacademy.ac.uk/system/files/resources/engagement through partnership.pdf

Horsfall, D. (2008). Bearing witness: Toward a pedagogical practice of love? Reflective Practice, 9(1), 1-10. https://doi.org/10.1080/14623940701816618

Jacobs, C. (1991). Violations of the supervisory relationship: An ethical and educational blind spot. Social Work, 36(2), 130-135. https://doi.org/10.1093/sw/36.2.130

Johnson, L., Lee, A., \& Green, B. (2000). The PhD and the autonomous self: Gender, rationality and postgraduate pedagogy. Studies in Higher Education, 25(2), 135-147. https://doi.org/10.1080/713696141

Kreber, C. (2013). Authenticity in and through teaching in higher education: The transformative potential of the scholarship of teaching. Routledge.

Kreber, C. (2015). Furthering the "theory debate" in the scholarship of teaching: A proposal based on Macintyre's account of practices. Canadian Journal of Higher Education, 45(2), 99-115.

Lechuga, V. M. (2011). Faculty-graduate student mentoring relationships: Mentors' perceived roles and responsibilities. Higher Education, 62(6), 757-771. https://doi.org/10.1007/s10734-011-9416-0

Lee, A. (2008). How are doctoral students supervised? Concepts of doctoral research supervision. Studies in Higher Education, 33(3), 267-281. https://doi.org/10.1080/03075070802049202

Lunsford, L. (2012). Doctoral advising or mentoring? Effects on student outcomes. Mentorship Tutoring Partnership and Learning, 20(2), 251270. https://doi.org/10.1080/13611267.2012.678974

Manathunga, C. (2012). Supervisors watching supervisors: The deconstructive possibilities and tensions of team supervision. The Australian Universities' Review, 54(1), 29-37.

Mansson, D. H., \& Myers, S. A. (2012). Using mentoring enactment theory to explore the doctoral student-advisor mentoring relationship. Communication Education, 61(4), 309-334. https://doi.org/10.1080/03634523.2012.708424

McCallin, A., \& Nayar, S. (2012). Postgraduate research supervision: A critical review of current practice. Teaching in Higher Education, 17(1), 63-74. https://doi.org/10.1080/13562517.2011.590979 
Moules, N. J., McCaffrey, G., Field, J. C., \& Laing, C. M. (2015). Conducting hermeneutic research: From philosophy to practice. Peter Lang.

Omar, F., Mahone, J. P., Ngobia, J., \& FitzSimons, J. (2016). Building rapport between international graduate students and their faculty advisors: Crosscultural mentoring relationships at the University of Guelph. The Canadian Journal for the Scholarship of Teaching and Learning, 7(2), 217. https://doi.org/10.5206/cjsotl-rcacea.2016.2.8

Paglis, L. L., Green, S. G., \& Bauer, T. N. (2006). Does adviser mentoring add value? A longitudinal study of mentoring and doctoral student outcomes. Research in Higher Education, 47(4), 451-476. https://doi.org/10.1007/s11162-005-9003-2

Poole, G. (2018). Using intuition, anecdote, and observation: Rich sources of SoTL projects. In N. L. Chick (Ed.), SoTL in action: Illuminating critical moments of practice (pp. 7-14). Stylus.

Richards, K. A. R., \& Fletcher, T. (2020). Learning to work together: Conceptualizing doctoral supervision as a critical friendship. Sport, Education and Society, 25(1), 98-110. https://doi.org/10.1080/13573322.2018.1554561

Roach, A., Christensen, B. K., Rieger, E., \& Graham, S. (2019). The essential ingredients of research supervision: A discrete-choice experiment. Journal of Educational Psychology, 111(7), 1243-1260. https://doi.org/10.1037/edu0000322

Rugg, G., \& Petre, M. (2004). The unwritten rules of PhD research. Open University Press.

Sarikaya, E. E., McAlpine, L., \& Amundsen, C. (2017). Doctoral students' experiences of feeling (or not) like an academic. International Journal of Doctoral Studies, 12, 73-90. https://doi.org/10.28945/3727

Sullivan, L. E., \& Ogloff, J. R. P. (1998). Appropriate supervisor-graduate student relationships. Ethics \& Behavior, 8(3), 229-248. https://doi.org/10.1207/s15327019eb0803 4

Sverdlik, A., Hall, N. C., McAlpine, L., \& Hubbard, K. (2018). The PhD experience: A review of the factors influencing doctoral students' completion, achievement, and well-being. International Journal of Doctoral Studies, 13, 361-388. https://doi.org/10.28945/4113

University of Calgary. (2018). Checklist of expectations for graduate students and supervisors. https://grad.ucalgary.ca/sites/default/files/teams/3/su studentsupervisor-checklist.pdf

Waghid, Y. (2006). Reclaiming freedom and friendship through postgraduate student supervision. Teaching in Higher Education, 11(4), 427-439. https://doi.org/10.1080/13562510600874185

Watts, J. H. (2008). Challenges of supervising part-time PhD students: Towards student-centred practice. Teaching in Higher Education, 13(3), 369-373. https://doi.org/10.1080/13562510802045402

Welikala, T., \& Atkin, C. (2014). Student co-inquirers: The challenges and benefits of inclusive research. International Journal of Research and 
Method in Education, 37(4), 390-406.

https://doi.org/10.1080/1743727X.2014.909402 